\title{
In Vitro Polyploidization of Thymus vulgaris L. and Its Effect on Composition of Essential Oils
}

\author{
Božena Navrátilová ${ }^{1}$, Michaela Švécarová ${ }^{1}$, Jan Bednářr ${ }^{2,3}$ and Vladan Ondřej ${ }^{1, *}$ \\ 1 Department of Botany, Faculty of Science, Palacký University, Šlechtitelů 27, 78371 Olomouc, Czech Republic; \\ bozena.navratilova@upol.cz (B.N.); michaela.svecarova@upol.cz (M.Š.) \\ 2 Global Change Research Institute CAS, Bělidla 986/4a, 60300 Brno, Czech Republic; bednar.j@czechglobe.cz \\ 3 Institute of Chemistry and Biochemistry, Faculty of Science, University of South Bohemia, \\ 37005 České Budějovice, Czech Republic \\ * Correspondence: vladan.ondrej@upol.cz; Tel.: +42-585-634-825
}

check for updates

Citation: Navrátilová, B.; Švécarová, M.; Bednář, J.; Ondřej, V. In Vitro Polyploidization of Thymus vulgaris L. and Its Effect on Composition of Essential Oils. Agronomy 2021, 11, 596. https://doi.org/ 10.3390/agronomy11030596

Academic Editors:

Małgorzata Podwyszyńska and Anna Trojak-Goluch

Received: 5 February 2021

Accepted: 18 March 2021

Published: 21 March 2021

Publisher's Note: MDPI stays neutral with regard to jurisdictional claims in published maps and institutional affiliations.

Copyright: (c) 2021 by the authors. Licensee MDPI, Basel, Switzerland. This article is an open access article distributed under the terms and conditions of the Creative Commons Attribution (CC BY) license (https:// creativecommons.org/licenses/by/ $4.0 /)$.

\begin{abstract}
The aim of this work was to find an effective protocol for in vitro propagation and to perform the in vitro polyploidization of diploid Thymus vulgaris $(2 n=30)$ using two experimental methods based on the use of oryzalin, an antimitotic agent. The ploidy level of the obtained shoots was checked by flow cytometric analysis. The most efficient conditions for inducing polyploidy were oryzalin concentrations of 0.346 and $1.73 \mathrm{mg} \mathrm{L}^{-1}$ present in the medium for two weeks. The vital polyploid shoots were multiplied for further evaluation, rooting and final transfer to nonsterile glasshouse and field conditions. The chemical compositions of the essential oils (EOs)—which were obtained from dried field grown plants by steam distillation-were analyzed by gas chromatography/mass spectrometry (GC/MS). The identified substances contributed approximately $95 \%$ to the total peak area. Statistical analysis revealed that the tetraploid subclone and the diploid reference plant do not differ in total terpene content, but they do differ in the relative proportions of all the individual terpenes with the exception of $\alpha$-pinene and UN5, indicating that both clones produce EOs of different quality. The obtained results showed the possibility of developing more efficient botanical insecticides based on EOs obtained from the tetraploid plants.
\end{abstract}

Keywords: botanical insecticides; chromosome doubling; essential oils; micropropagation; tetraploids; thyme

\section{Introduction}

Thyme (Thymus vulgaris L.) belongs to an important aromatic and medicinal genus of the family Lamiaceae. Thyme is a well-known historical medicinal and spice plant from the Mediterranean. The plant bodies contain a wide range of active substances and essential oils (EOs) including thymol, camphor, cineol, carvacrol, borneol, linalool, flavonoids, etc. [1-3]. Herbal medicines derived from thyme have been used to treat alopecia, bronchitis, cough, inflammations, skin infections, and gastrointestinal distress from ancient times [3]. The main component of T. vulgaris oil is thymol, which has been shown to have antibacterial, antifungal, antibiotic, antiseptic, and anti-inflammatory effects, resulting in its medicinal uses $[4,5]$. The genus Thymus L. contains about 215 species of herbaceous perennials and subshrubs [6].

Micropropagation is a method useful for the multiplication of selected genotypes and chemotypes of some medicinal and aromatic plant species [7]. Several studies have described procedures of in vitro propagation of thyme from seeds. Coelho et al. [8] described a protocol for the in vitro propagation of Thymus lotocephalus. The procedures of T. vulgaris propagation have been reported by several studies [9-11].

Methods of in vitro polyploidization using oryzalin are used to attempt to increase the amounts of the biologically active substances within thyme. The in vitro polyploidization with oryzalin has been described in several plant species for different tissues and 
organs $[12,13]$. The stock of natural resources to meet the ever-increasing demand in various industries is inadequate; therefore, suitable methods of micropropagation and polyploidization have been sought to increase the content of targeted desirable compounds in plants. In the past decades, the alkaloid colchicine was traditionally used for chromosome doubling in plants; however, it can cause side effects such as chromosome loss, rearrangements, and gene mutations $[14,15]$. Colchicine sometimes led to the sterility and abnormal growth of regenerated plants [16]; chromosome doubling can be performed with oryzalin at a much lower concentration than with colchicine. The herbicide oryzalin (3,5-dinitro-N4N4-dipropylsulfanilamide) has a greater affinity to plant cell tubulins than colchicine and has been preferentially used as a mitotic blocking agent [17], thus indicating its potential as a reagent for the in vitro induction of polyploids. Although, Tavan et al. [18] described the in vitro induction of polyploidy in Thymus persicus using colchicine, oryzalin has bigger potential for successful thyme polyploidization.

In this study, we describe an in vitro protocol for the micropropagation of the T. vulgaris cultivar 'Varico' to obtain sufficient homogenous plant material for in vitro polyploidization. The obtained tetraploid plants showed differences in the EOs spectrum. Altered EOs spectrum could increase efficacy of natural botanical insecticides compared with synthetic ones [19]. Here we demonstrated that the EO from tetraploid T. vulgaris displayed higher acute toxicity against the larvae Culex quinquefasciatus and Spodoptera littoralis than EO from diploid plants.

\section{Materials and Methods}

\subsection{Plant Material, Seed Germination and Shoot Multiplication}

Mature seeds of Thymus vulgaris cultivar 'Varico' were obtained from Roman Pavela, Secondary Plant Metabolites in Crop Protection, the Crop Research Institute (CRI), PragueRuzyně, Czech Republic. The seeds were surface sterilized in 70\% ethanol for $2 \mathrm{~min}$, then disinfected with $5 \%$ chloramine $\mathrm{T}$ (commercial agent) containing Tween-20 for $20 \mathrm{~min}$. Next, the seeds were rinsed three times in sterile distilled water and then germinated in Petri dishes (6 cm, 10 seeds) on Murashige and Skoog (MS) [20] medium including vitamins and containing $30 \mathrm{~g} \mathrm{~L}^{-1}$ sucrose and $8 \mathrm{~g} \mathrm{~L}^{-1}$ agar (Duchefa, the Netherlands). The medium was supplemented with: $0.01 \mathrm{mg} \mathrm{L}^{-1}$ indole-3-butyric acid (IBA), $0.01 \mathrm{mg} \mathrm{L}^{-1}$ 6-benzyladenine (BA) (both from Duchefa, the Netherlands), and 0.1\% Plant Preservative Mixture (PPM), (Plant Cell Technology, Inc.). pH of MS medium was adjusted on 5.8.

The Petri dishes with seeds were placed in the dark for three days (thermostat, $25^{\circ} \mathrm{C}$ ) and then transferred to the culture room (growth chamber at $22 \pm 2{ }^{\circ} \mathrm{C}$, with a photoperiod of $16 \mathrm{~h} \mathrm{light} / 8 \mathrm{~h}$ dark and light intensity of $32-36 \mu \mathrm{mol} \mathrm{m}^{-2} \mathrm{~s}^{-1}$ ). After germination the plantlets, which were without internal contamination, were multiplied. Every 6 weeks, the shoots were repeatedly cut into $20-30 \mathrm{~mm}$ long segments and subcultured so that a clone could emerge from each seed, onto MS medium (see above), supplemented with $0.1 \mathrm{mg} \mathrm{L}^{-1}$ IBA, $0.1 \mathrm{mg} \mathrm{L}^{-1}$ BA, and $20 \mathrm{mg} \mathrm{L}^{-1}$ ascorbic acid in the Erlenmeyer flasks $(100 \mathrm{~mL}$ flask volume, medium $30 \mathrm{~mL}, 5-6$ shoots). During culturing, the side branches were separated and placed on the medium to achieve a sufficient number of plants originating from one seed (50-60 plants). Prior to initiating the in vitro polyploidization experiment, the plants were cultured on MS medium, supplemented with $0.01 \mathrm{mg} \mathrm{L}^{-1} \mathrm{IBA}, 0.01 \mathrm{mg} \mathrm{L}^{-1} \mathrm{BA}$, and $20 \mathrm{mgL}^{-1}$ ascorbic acid in the Erlenmeyer flasks $(100 \mathrm{~mL}$ volume, medium $30 \mathrm{~mL}$, $5-6$ shoots).

\subsection{In Vitro Polyploidization}

Nodal segments of two well-growing and multiplying clones (Nos. 8 and 15) were selected for the in vitro polyploidization experiment. The third to fifth nodal segments from the apex of donor plants, with one pair of leaves without visible axillary buds, were used as explants. The stock solution of oryzalin (Sigma-Aldrich, St. Louis, MO, USA) was prepared according to Greplová et al. [21] and the respective concentrations of oryzalin for the experiments were prepared from this stock solution. 
(1) Cultivation of nodal segments on oryzalin medium for 2 weeks (CMNS)

Nodal segments (10-15 pieces) were placed in Erlenmeyer flasks on hormone-free MS medium supplemented with different concentrations of oryzalin $(0.346,1.73$, and $3.46 \mathrm{mg} \mathrm{L}^{-1}$ ) and medium without oryzalin as control. For 2 weeks, segments were cultivated in the thermostat at $25{ }^{\circ} \mathrm{C}$ and then transferred on MS medium with $0.01 \mathrm{mg} \mathrm{L}^{-1}$ IBA, $0.01 \mathrm{mg} \mathrm{L}^{-1} \mathrm{BA}$ and $30 \mathrm{mg} \mathrm{L}^{-1}$ ascorbic acid in tubes. Plant material was then subcultured every four weeks. The experiment was repeated three times for both clones.

(2) Overflow of nodal segments with oryzalin solution for $24 \mathrm{~h}$ (ONS)

Nodal segments (10-15 pieces) were placed on hormone-free MS medium in Erlenmeyer flasks and then were covered with the oryzalin solution for $24 \mathrm{~h}$; and sterile distilled water for the control. Concentrations of used oryzalin solutions were 1.73, 3.46, 5.19, 6.92, and $8.65 \mathrm{mg} \mathrm{L}^{-1}$ for clone No. 8; those of 5.19, 6.92, and $8.65 \mathrm{mg} \mathrm{L}^{-1}$ for clone No. 15. The segments were incubated in a thermostat at $25^{\circ} \mathrm{C}$. After treatment, the oryzalin solution was removed and the nodal segments were washed three times in sterile distilled water and transferred onto MS medium with $0.01 \mathrm{mg} \mathrm{L}^{-1} \mathrm{IBA}, 0.01 \mathrm{mg} \mathrm{L}^{-1} \mathrm{BA}$ and $20 \mathrm{mg} \mathrm{L}^{-1}$ ascorbic acid in Petri dishes $(6 \mathrm{~cm}, 6$ segments) for 2 weeks and then subcultured every 4 weeks in the tubes. The experiment was repeated two times for both clones and statistically evaluated using one-way ANOVA test; using the Past 4.3 program (Hammer O., 2020)

The shoots, each developing from a single axillary bud, influenced by oryzalin, were numbered and registered as subclones. After six months of cultivation, the shoots that were suspected to be tetraploids were selected for cytometric analysis based on morphological observations (e.g., dark green leaves, shorter internodes).

\subsection{Multiplication of Polyploid Plants, Rooting and Acclimatization}

The growing shoots obtained from the oryzalin experiments were evaluated by flow cytometry and only polyploid and diploid reference plants were cultured. Diploid regenerants were excluded. Polyploid plants were multiplied on MS medium with $0.01 \mathrm{mg} \mathrm{L}^{-1}$ IBA, $0.01 \mathrm{mg} \mathrm{L}^{-1} \mathrm{BA}$, and $20 \mathrm{mg} \mathrm{L}^{-1}$ ascorbic acid in tubes. The polyploid shoots were subcultured every five weeks. Long shoots were cut into $4-5 \mathrm{~cm}$ long segments and stripped of yellowish or blackened leaves. The shoots were rooted on hormone-free MS medium and transferred to the culture room. The prepared plants were planted in Jiffy pellets, placed into plastic mini-greenhouses that were transferred into the greenhouse for 6-10 weeks. Vigorous, well rooted plants were planted into a field.

\subsection{Flow Cytometry (FCM)}

DNA-ploidy levels of the in vitro shoots, obtained after oryzalin treatments were analyzed by flow cytometry using the method of internal standardization. The measurements were performed with a Partec CyFlow ML (Partec GmbH, Münster, Germany) equipped with a Partec UV LED kit (365 nm, 10 mW) (Partec GmbH, Münster, Germany). The data obtained were evaluated using FloMax Software, version 2.9. To extract the plant nuclei, 2-3 young leaves of a T. vulgaris in vitro sample, with a similar amount of the internal standard tissue, Zea mays CE-777 ( $2 \mathrm{C}=5.43 \mathrm{pg}$ DNA), were cut with a sharp razor blade in a Petri dish containing $1.5 \mathrm{~mL}$ of ice cold LB01 buffer, pH 7.8 [22]. Then, the crude suspension of nuclei was filtered through a $22 \mu \mathrm{m}$ nylon mesh. The isolated nuclei were treated with $50 \mu \mathrm{L}$ of RNase $\left(1 \mathrm{mg} \mathrm{mL}^{-1}\right)$ and stained with $50 \mu \mathrm{L}$ of $4^{\prime}$,6-diamidino-2-phenylindole (DAPI), then incubated at room temperature for $5 \mathrm{~min}$. For each sample, 3000 particles were measured and histograms of the fluorescence intensity were registered over 512 channels. The first peak in the histogram corresponded to the G1 (2C-sample) phase of the cell cycle of T. vulgaris. The ploidy level is defined by comparing the position of the G1 peaks with respect to the position of standard. 


\subsection{Gas Chromatography/Mass Spectrometry (GC/MS)}

The terpene composition of thyme EOs was analyzed on a Trace GC Ultra (Thermo Fischer Scientific, Waltham, MA, USA) equipped with a SKY liner, splitless, $3 \times 0.8 \times 105 \mathrm{~mm}$ (Restek Corporation, Bellefonte, PA, USA) and Restek fused silica capillary column Rxi-5ms, $30 \mathrm{~m} \times 0.25 \mathrm{~mm} \times 0.25 \mu \mathrm{m}$ (Restek Corporation, Bellefonte, PA, USA), and coupled with a mass selective detector ISQ (Thermo Fischer Scientific, Waltham, MA, USA). Helium was used as the carrier gas with an inlet flowrate of $1 \mathrm{~mL} \mathrm{~min}{ }^{-1}$. Prior to injection, the EO samples were diluted in two steps: $2 \mu \mathrm{L}$ of EO aliquot was diluted by $998 \mu \mathrm{L}$ of hexane, and then $10 \mu \mathrm{L}$ of this mixture was diluted by $990 \mu \mathrm{L}$ of hexane with added internal standard (eucalyptol $2 \mu \mathrm{g} \mathrm{mL}^{-1}$ ). The samples were prepared in triplicates. The $1 \mu \mathrm{L}$ solution was injected in splitless mode at a $250{ }^{\circ} \mathrm{C}$ inlet temperature; after $1 \mathrm{~min}$, the split ratio was set to 1:50 $\mathrm{mL} \mathrm{min}^{-1}$. The oven temperature was programmed as follows: $40^{\circ} \mathrm{C}$ for $5 \mathrm{~min}$, then increased to $150{ }^{\circ} \mathrm{C}$ at a rate $3^{\circ} \mathrm{C} \mathrm{min}-1$, then increased to $250{ }^{\circ} \mathrm{C}$ at a rate $10^{\circ} \mathrm{C} \mathrm{min}-1$, and then increased to $290^{\circ} \mathrm{C}$ at a rate of $25^{\circ} \mathrm{C}$. The final temperature was held for $2 \mathrm{~min}$. The transfer line and ion source temperatures were set to 250 and $200^{\circ} \mathrm{C}$, respectively. The obtained results were evaluated using Statistica 13 and Canoco 5 software.

\subsection{Insects}

We used early 3rd instar Culex quinquefasciatus larvae, which were reared in the laboratory (CRI). The larvae were fed on dog biscuits and yeast powder in a 3:1 ratio. The adult larvae were provided with a $10 \%$ sucrose solution $\left(\mathrm{w} . \mathrm{v}^{-1}\right.$ ) and 1 week old chicks for blood feeding. Larvae of the tobacco cutworm Spodoptera littoralis were acquired from an established laboratory population ( $>20$ generations; outcrossed once) and fed on an artificial insect diet (Stonefly Industries, Bryan, TX, USA). For the study, the early 3rd instar S. littoralis larvae were used. All used insects were kept under controlled conditions $\left(25 \pm 1{ }^{\circ} \mathrm{C}, 70 \% \pm 3 \%\right.$ relative humidity and $16 \mathrm{~h}$ light photoperiod).

\subsection{Acute Toxicity on C. quinquefasciatus and S. littoralis}

With a few minor adjustments, the mosquito larvicidal trials were executed according to WHO (1996) standard procedures [23]. The EO was obtained from the aerial part of T. vulgaris cultivar 'Varico' clone 15, diploid reference and tetraploid plants (sample 22). The harvested plants were cultivated two months on the experimental field of the CRI (Olomouc, Czech Republic). The hydrodistillation method was performed according to the method described by Pavela and Sedlak [19]. The thyme EOs were diluted in dimethyl sulfoxide, preparing serial dilutions of test dosages to study the acute toxicity on C. quinquefasciatus. We added $1 \mathrm{~mL}$ of serial dilutions to $224 \mathrm{~mL}$ of distilled water in a $500 \mathrm{~mL}$ glass bowl, which we shook gently, for each experimental treatment. The selected larvae were transferred into a bowl containing the test solution with a final surface area of $125 \mathrm{~cm}^{2}$ (25 larvae/beaker). Mortality was evaluated after $24 \mathrm{~h}$ of exposure without larvae feeding [23]. Acute toxicity to the $3 r d$ instar of S. littoralis larvae was measured as mortality after $24 \mathrm{~h}$ of exposure to the thyme EO applied according to the study [24]. The lethal dose was calculated using five doses of the oil and four duplicate measurements of 20 larvae tested for each dose. Growth rooms with constant relative humidity $70 \% \pm 3 \%$; a $16 \mathrm{~h}$ light photoperiod and varied temperatures of $15,20,25$, and $30 \pm 1{ }^{\circ} \mathrm{C}$, were used. Experimental testing showed that over $20 \%$ of the controlled mortality was discharged and repeated. When the level of controlled mortality was at $1-20 \%$, the observed mortality was corrected by Abbott's formula [25]. Using probit analysis, the LC50 and LC90 regression equations, as well as the $95 \%$ confidence limit, were then calculated.

\section{Results}

\subsection{Multiplication}

The minimum differences between the two selected clones (Nos. 8 and 15) were found. Clone No. 8 had longer shoots (more than $1 \mathrm{~cm}$ ) and showed an average multiplication of 
7.45 shoots per explant. Clone No. 15 showed an average multiplication of 6.60 shoots per explant. Sufficient numbers of plants for polyploidization were prepared.

\subsection{In Vitro Polyploidization, Ploidy Determination}

For clone No. 8, 143 nodal segments were used in the experimental cultivation on oryzalin medium (CMNS), and, in total, 28 surviving explants were obtained, of which seven were determined as tetraploids based on FCM (Table 1, Figure 1). We found that $3.46 \mathrm{mg} \mathrm{L}^{-1}$ oryzalin was lethal and plants became necrotic. In the second polyploidization method, ONS, 130 nodal segments were treated with oryzalin and, in total, 22 surviving shoots were obtained, of which three shoots were tetraploid (Table 1). With this method, the $5.19,6.92$, and $8.65 \mathrm{mg} \mathrm{L}^{-1}$ concentrations of oryzalin were lethal.

Table 1. Numbers of thyme tetraploids obtained from in vitro polyploidization using two methods: (1) cultivation of nodal segments on oryzalin medium for two weeks and (2) overflow of nodal segments with oryzalin solution for $24 \mathrm{~h}$.

\section{Cultivation of Nodal Segments on Oryzalin Medium for 2 Weeks}

\begin{tabular}{|c|c|c|c|c|c|c|}
\hline \multirow{2}{*}{$\begin{array}{l}\text { Oryzalin } \\
\left(\mathrm{mg} \mathrm{L}^{-1}\right)\end{array}$} & \multicolumn{2}{|c|}{ No. of Explants } & \multicolumn{2}{|c|}{ Viable Explants (\%) } & \multicolumn{2}{|c|}{ No. of Tetraploids (\%) } \\
\hline & Clone 8 & Clone 15 & Clone 8 & Clone 15 & Clone 8 & Clone 15 \\
\hline 0.346 & 45 & 28 & $19(42.2)$ & $15(53.6)$ & $3(15.8)$ & $6(40.0)$ \\
\hline 1.73 & 50 & 29 & $9(18.0)$ & $3(10.3)$ & $4(44.4)$ & $2(66.7)$ \\
\hline 3.46 & 48 & 29 & $0(0)$ & $0(0)$ & $0(0)$ & $0(0)$ \\
\hline total & 143 & 86 & $28(19.6)$ & $18(20.2)$ & $7(25.0)$ & $8(44.4)$ \\
\hline control & 20 & 20 & $20(100)$ & $20(100)$ & $0(0)$ & $0(0)$ \\
\hline \multicolumn{7}{|c|}{ Overflow of nodal segments with oryzalin solution for $24 \mathrm{~h}$} \\
\hline 1.73 & 33 & * & $14(42.2)$ & * & $1(7.1)$ & * \\
\hline 3.46 & 32 & * & $8(28.1)$ & * & $2(25.0)$ & * \\
\hline 5.19 & 20 & 22 & $0(0)$ & $1(4.5)$ & $0(0)$ & $0(0)$ \\
\hline 6.92 & 25 & 20 & $0(0)$ & $0(0)$ & $0(0)$ & $0(0)$ \\
\hline 8.65 & 20 & 21 & $0(0)$ & $0(0)$ & $0(0)$ & $0(0)$ \\
\hline total & 130 & 63 & $22(16.9)$ & $1(1.6)$ & $3(13.6)$ & $0(0)$ \\
\hline control & 10 & 10 & $10(100)$ & $10(100)$ & $0(0)$ & $0(0)$ \\
\hline
\end{tabular}

* means no nodal segments for this part of experiment.
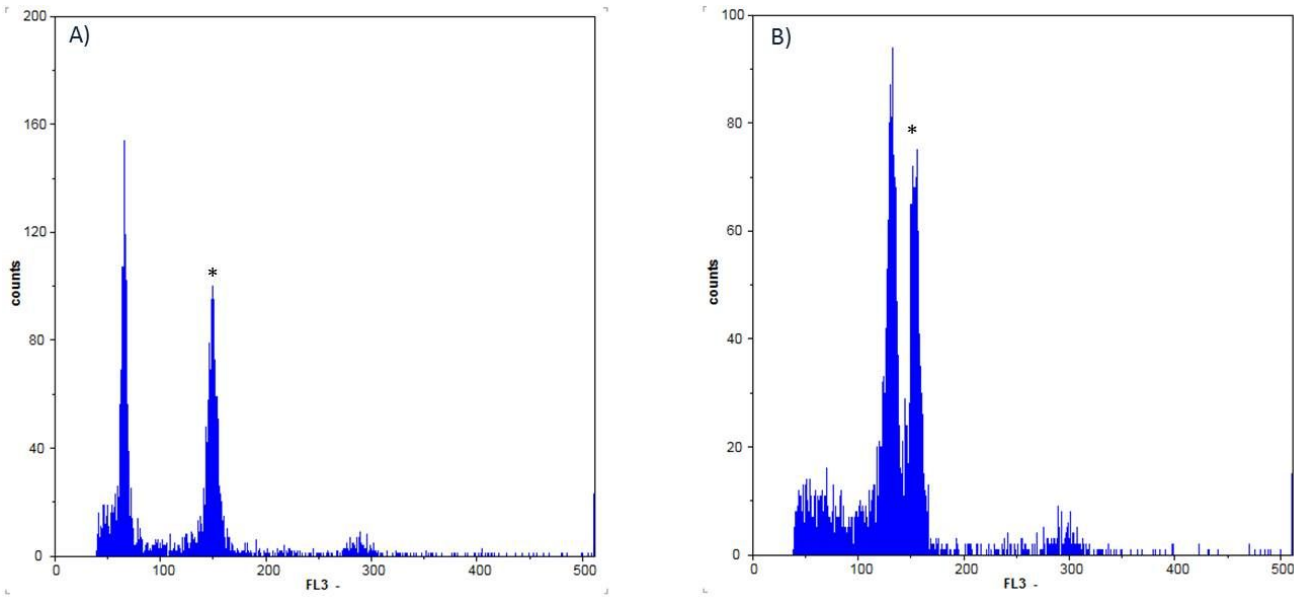

Figure 1. Representative flow cytometric histograms of nuclear DNA contents of T. vulgaris. (A) diploid reference plant and internal standard Zea mays * and (B) tetraploid originated from clone No. 8 and standard Zea mays *. 
A large number of tetraploid shoots of thyme was achieved for clone No. 15 (Table 1). The total number of nodal segments in the CMNS experiments were 86 , and 18 surviving explants were obtained, eight of which were tetraploids (44.44\%). The highest number of tetraploid shoots (six plantlets) were obtained after treatment with oryzalin at a concentration of $0.346 \mathrm{mg} \mathrm{L}^{-1}$, followed by two tetraploids at $1.73 \mathrm{mg} \mathrm{L}^{-1}$ oryzalin (Table 1). The $3.46 \mathrm{mg} \mathrm{L}^{-1}$ concentration was also lethal as it was observed for clone No. 8. Each tetraploid explant from both clones was propagated as a subclone. Statistical comparison of tetraploid yields between clones and methods of polyploidization was significant only for between numbers of tetraploids from CMNS and ONS procedures $(p=0.031)$, where the CMNS procedure was more successful.

Based upon visual evaluations of in vitro plant morphology, several differences between the tetraploids and diploids were observed. Most of tetraploids had shorter internodes, darker and rounded leaves, more compact appearance and some of the tetraploids rooted poorly (Figure 2). During 3-5 months after exposure to oryzalin, the growth of the tetraploids was noticeably slower than diploids. In contrast, the tetraploids growing ex vitro (greenhouse and field) showed lush growth comparing with diploids (Figure 3).

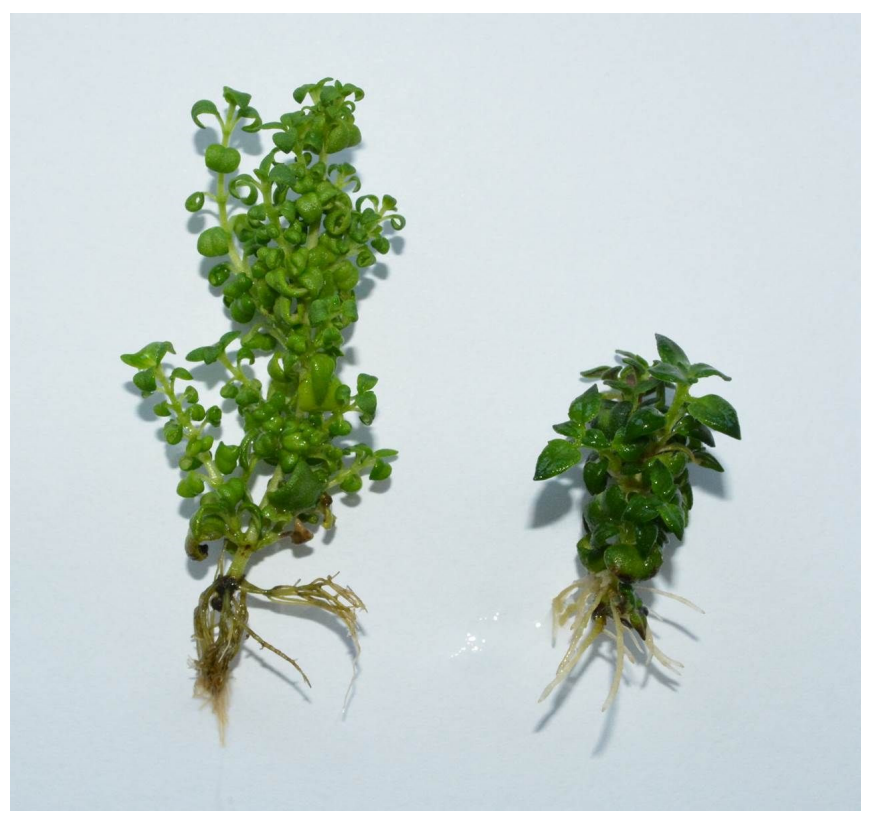

Figure 2. Diploid (left) and tetraploid (right) plants of T. vulgaris subclone TR15-22 after five months growing in vitro.

\subsection{EO Chemical Composition}

Firstly, the differences in the total sum of all 16 peak areas were tested by one way ANOVA between the tetraploid subclone (TR15-22) and its diploid reference sample (TR15$\mathrm{K})$. The EOs from the tetraploid subclone and the diploid reference subclone did not differ in total terpenes content $(\mathrm{F}=0.235, \mathrm{DF}=1.4 p=0.6534)$. However, statistical comparison of single analyte concentrations revealed that all the terpenes significantly differed between the clones, except for $\alpha$-pinene and UN5. The EO from the tetraploid subclone contained significantly higher proportions of thymol, carvacrol, trans-caryophyllene, UN3 and UN4 (Table 2). Principal component analysis (PCA) on the normalized peak areas was performed for a graphical illustration of the differences between TR15-22 and TR15-K (Figure 4). Principal component 1 explained $97.8 \%$ of the variability and largely corresponded with differences between the clones, as indicated by the correlation of most analytes with the first principal component. The only exception was analyte UN5. However, this analyte occurred in the samples in very low amounts. The second principal component 
explained only a small part of the variability and corresponded with the variability between sample replicates.

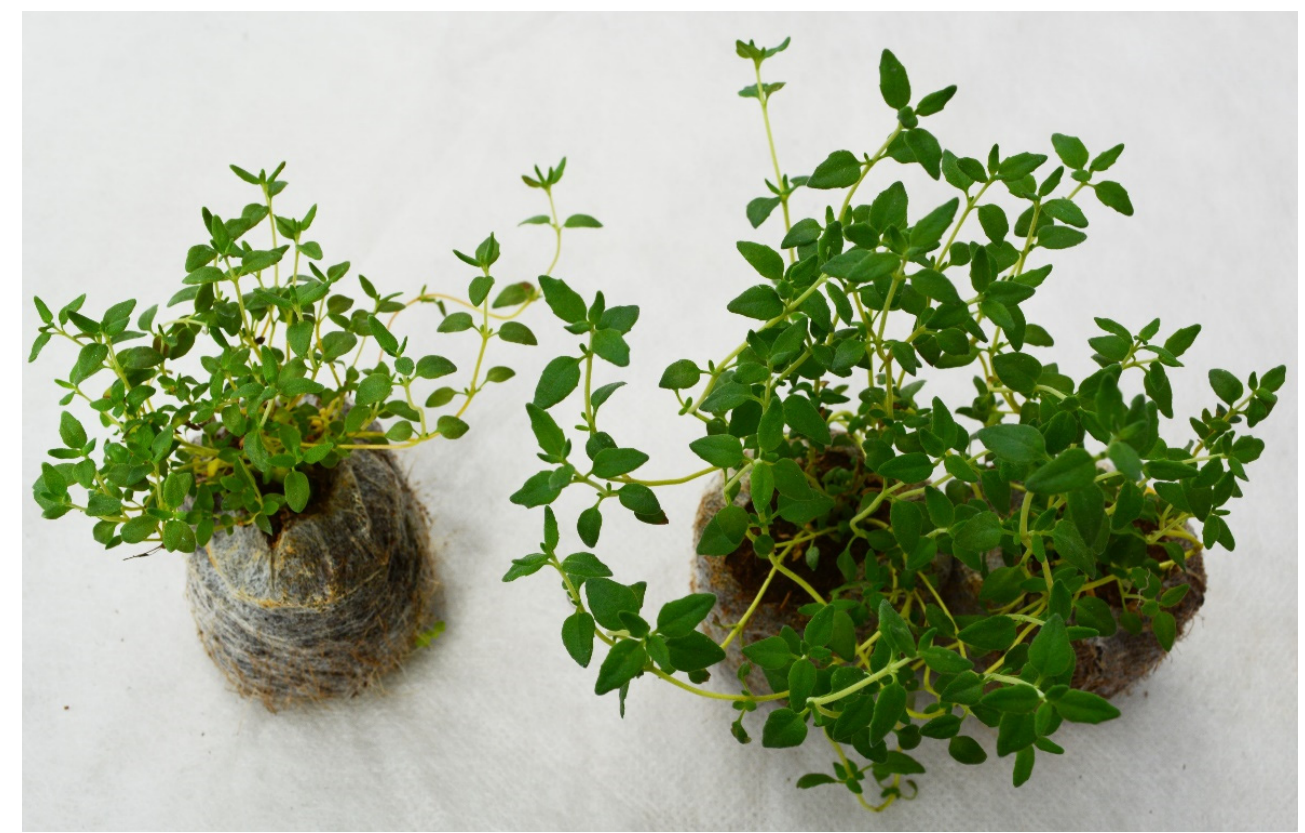

Figure 3. Plants of T. vulgaris in Jiffy pellets growing for two months ex vitro: diploid (left) and two tetraploid (right) plants from subclone TR15-22.

Table 2. Abundances of individual terpenes found in tetraploid subclone TR15-22 and the diploid reference subclone TR15-K: mean of normalized peak area (\%) and relative standard deviation (RSD), together with statistical evaluation of differences between the two clones (ANOVA). The abundances of compounds found in higher amounts in the tetraploid subclone TR15-22 are marked in bold.

\begin{tabular}{|c|c|c|c|c|c|c|c|}
\hline \multirow[t]{2}{*}{ Terpenes } & \multicolumn{2}{|c|}{ TR15-K } & \multicolumn{2}{|c|}{ TR15-22 } & \multicolumn{3}{|c|}{ ANOVA } \\
\hline & Area [\%] & RSD [\%] & Area [\%] & RSD [\%] & DF & $\mathbf{F}$ & $p$ \\
\hline UN1 & 1.74 & 5.19 & 1.49 & 5.41 & $1 ; 4$ & 143.0 & 0.0003 \\
\hline$\alpha$-Pinene & 0.71 & 5.65 & 0.64 & 2.23 & $1 ; 4$ & 4.8 & 0.0936 \\
\hline Myrcene + UN & 1.56 & 4.34 & 1.36 & 3.76 & $1 ; 4$ & 18.6 & 0.0138 \\
\hline UN2 & 2.96 & 4.51 & 2.4 & 3.74 & $1 ; 4$ & 148.6 & 0.0003 \\
\hline 4-Cymene & 14.94 & 4.31 & 12.39 & 4.64 & $1 ; 4$ & 162.8 & 0.0002 \\
\hline$\gamma$-Terpinene & 20.66 & 5.17 & 17.78 & 4.96 & $1 ; 4$ & 347.3 & $<0.0001$ \\
\hline UN3 & 0.48 & 7.45 & 0.78 & 4.17 & $1 ; 4$ & 224.7 & 0.0001 \\
\hline UN4 & 0.08 & 3.29 & 0.09 & 7.29 & $1 ; 4$ & 22.3 & 0.0091 \\
\hline Linalool & 1.52 & 5.88 & 1.1 & 5.41 & $1 ; 4$ & 9621.9 & $<0.0001$ \\
\hline Camphor & 0.43 & 7.55 & 0.28 & 4.56 & $1 ; 4$ & 619.85 & $<0.0001$ \\
\hline Borneol & 0.32 & 4.5 & 0.21 & 6.18 & $1 ; 4$ & 124.7 & 0.0004 \\
\hline Terpinen-4-ol & 0.66 & 6.58 & 0.31 & 5.04 & $1 ; 4$ & 2231.4 & $<0.0001$ \\
\hline UN5 & 0.13 & 6.6 & 0.13 & 15.14 & $1 ; 4$ & 0.0 & 0.9308 \\
\hline Thymol & 52.34 & 6.93 & 58.95 & 6.24 & $1 ; 4$ & 240.3 & 0.0001 \\
\hline Carvacrol & 0.95 & 10.94 & 1.2 & 9.73 & $1 ; 4$ & 25.7 & 0.0071 \\
\hline trans-Caryophyllene & 0.52 & 6.6 & 0.88 & 5.56 & $1 ; 4$ & 22345.4 & $<0.0001$ \\
\hline
\end{tabular}




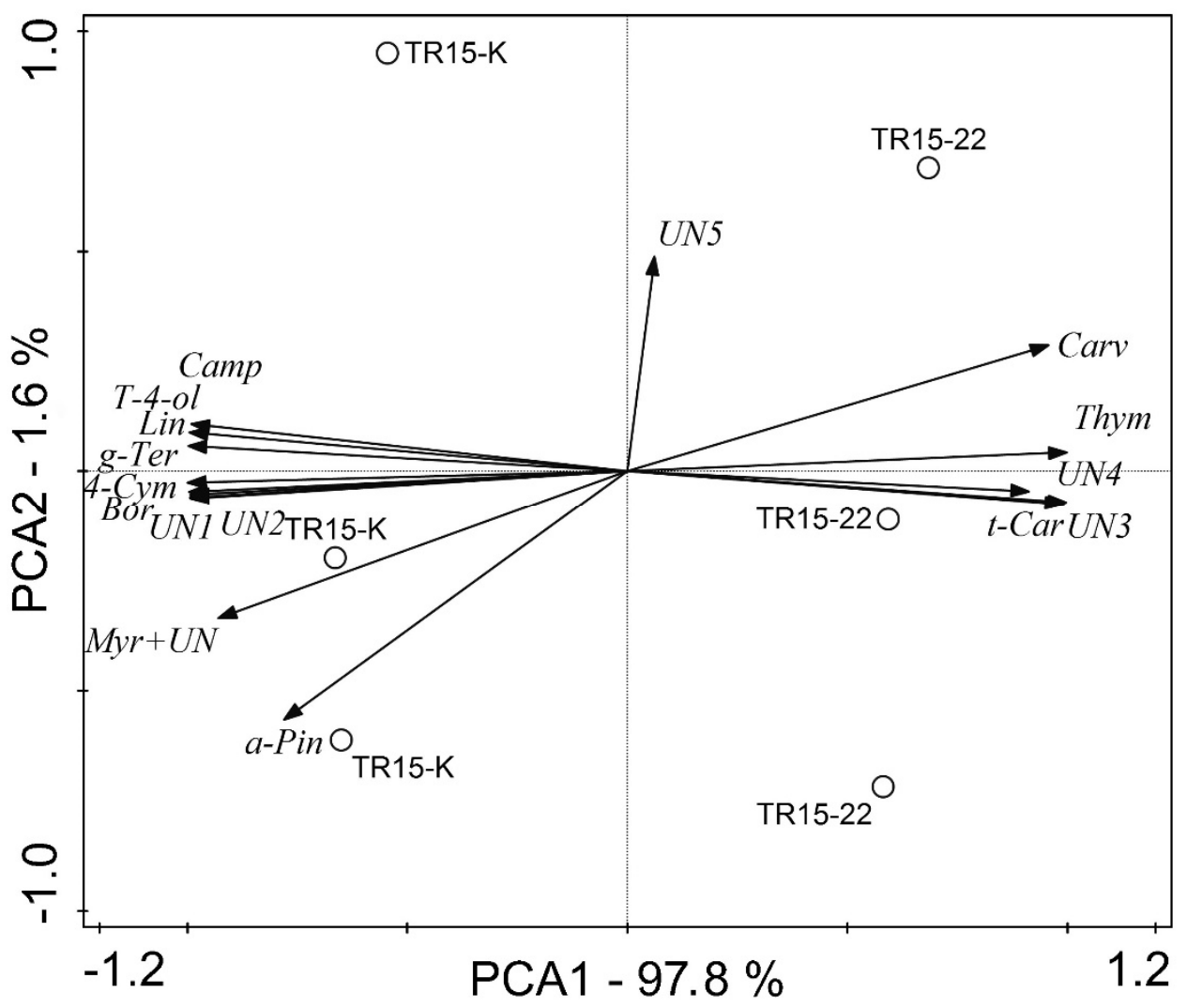

Figure 4. Principal component analysis (PCA) on relative abundances of individual terpenes in essential oil from tetraploid subclone (TR15-22) and the diploid reference subclone (TR15-K). Bor, borneol; Camp, camphor; Carv, carvacrol; $\alpha$-Pin, a-pinene; $t$-Car, trans-caryophyllene; 4-Cym, 4-cymene; Lin, linalool; Myr + UN, myrcene + UN; $\gamma$-Ter, g-terpinene; T-4-ol, terpinen-4-ol; Thym, thymol; UN1-5, unknown compound 1-5.

\subsection{Acute Toxicity on C. quinquefasciatus and S. littoralis}

The effectiveness of thyme essential oil in terms of acute toxicity toward C. quinquefasciatus and S. littoralis is presented in Table 3. Based on a comparison of the lethal doses, the thyme essential oil isolated from the thyme tetraploid plant (TR15-22) was more effective than of the diploid reference plant; LD50 was estimated at 36.3 and $45.2 \mu \mathrm{g}^{1} \mathrm{larvae}^{-1}$ for S. littoralis and 25.5 and $28.9 \mu \mathrm{g} \mathrm{L}^{-1}$ for C. quinquefasciatus. Acute toxicity experiments showed that the highest effectiveness was obtained for C. quinquefasciatus larvae by tetraploid Thymus vulgaris essential oil (LD50 $\left.=25.5 \mu \mathrm{g} \mathrm{L}^{-1}\right)$.

Table 3. Insecticidal activity of essential oil from tetraploid and diploid T. vulgaris.

\begin{tabular}{|c|c|c|c|c|c|c|c|c|c|c|c|}
\hline \multirow[b]{2}{*}{ Insect } & \multicolumn{6}{|c|}{ TR15-K } & \multicolumn{5}{|c|}{ TR15-22 } \\
\hline & & $\mathrm{LC}_{50}$ & $\mathrm{CI}_{95}$ & $\mathrm{LC}_{90}$ & $\mathrm{CI}_{95}$ & Chi & $\mathrm{LD}_{50}$ & $\mathrm{CI}_{95}$ & $\mathrm{LD}_{90}$ & $\mathrm{CI}_{95}$ & Chi \\
\hline Spodoptera littoralis & $\mu$ g.larvae ${ }^{-1}$ & 45.2 & $41.1-50.8$ & 61.7 & $57.8-72.1$ & 3.532 & 36.3 & $32.2-39.1$ & 52.5 & $48.5-55.3$ & 1.263 \\
\hline Culex quinquefqsciatus & $\mu \mathrm{g} \mathrm{L}^{-1}$ & 28.9 & $26.5-33.8$ & 45.5 & $41.1-47.5$ & 2.253 & 25.5 & $22.3-28.7$ & 39.2 & $36.8-43.5$ & 0.711 \\
\hline
\end{tabular}

\section{Discussion}

Chromosome doubling often leads to anatomical and morphological changes such as alteration in the leaf shape and thickness, plant architecture or organ size as well as secondary metabolite contents $[18,26,27]$. The process of polyploidization is influenced by various factors such as genotype, explant type, application method with selection of a suitable agent, the agent's optimal concentration and agent's duration of action, because very low concentrations are insufficient and too high of a concentration is lethal [28]. The antimitotic agents can be applied directly to the culture medium $[14,28,29]$, or as an 
aqueous solution. Explants used for polyploidization are usually nodal segments from in vitro growing plants [21,30] or shoot tips [18]. Moreover, the in vitro method of mitotic polyploidization requires a sufficient number of vital and identical plant materials for the preparation of nodal segments with dormant buds. This is why we prepared a high number of explants originating maximally from the two best-growing clones. The choice of the agent as well as a suitable concentration of the agent plays an important role in obtaining polyploid plants. In our experiments, the high concentrations of oryzalin negatively influenced the regeneration of shoots from the nodal segments of thyme. We showed that lower concentrations of oryzalin are more effective than higher ones. Surprisingly, similar work on T. vulgaris [31] reported an effective concentration of oryzalin for polyploidization of $27.68 \mathrm{mg} \mathrm{L}^{-1}$. Although this concentration is much higher than those we used, they obtained three tetraploids from 40 treated explants. The time of treatment probably plays an important role in successful polyploidization. Tavan et al. [18] described the in vitro induction of polyploidization using four concentrations of colchicine on shoot tips with an in vitro regenerated clone of Thymus persicus. From 960 shoot tip segments, they obtained $1.04 \%$ tetraploid and mixoploid plants. However, in our experiments using oryzalin, only homogeneous tetraploid plants were detected. Colchicine and oryzalin were used for in vitro polyploidization of nodal buds of Pfaffia glomerata by Gomes et al. [30] at various concentrations in culture medium for one and two weeks. Oryzalin (3.46-10.38 $\mathrm{mg} \mathrm{L}^{-1}$ ) only induced diploid and mixoploid plants, but colchicine (3.46-10.38 $\mathrm{mg} \mathrm{L}^{-1}$ ) induced tetraploid plants after one week in culture. On the other hand, Greplová et al. [21] compared the efficacy of colchicine and oryzalin for in vitro polyploidization of some wild Solanum species: the yield of tetraploids using colchicine $(8.6 \%)$ was lower than that for oryzalin treatment $(10.1 \%)$.

Several authors reported good results using oryzalin as an antimitotic agent. For example by Viehmannová et al. [27] used oryzalin as an effective antimicrotubule agent in Ullucus tuberosus, where the most efficient concentration was $6.92 \mathrm{mg} \mathrm{L}^{-1}$ oryzalin for $24 \mathrm{~h}$ and the polyploidization efficiency was $11.11 \%$. Another study described chromosome duplication in Chaenomeles japonica, with concentrations of $10.38-13.84 \mathrm{mg} \mathrm{L}^{-1}$ oryzalin being most effective [32]; in Paspalum notatum [33], $6.92 \mathrm{mg} \mathrm{L}^{-1}$ oryzalin displayed the highest chromosome duplication efficiency. Low concentrations of oryzalin (0.346-3.46 mg $\mathrm{L}^{-1}$ ) were used in successful polyploidization in Ajuga reptans [34] and Humulus lupulus [35]. In another work [15], the authors described oryzalin-induced chromosome doubling in Rosa, the selected concentrations of oryzalin were 1.73 and $5.19 \mathrm{mg} \mathrm{L}^{-1}$.

Here, we noted changes in the EOs in thyme tetraploids in comparison with diploids. It is generally accepted that genetic improvement as chromosome doubling could alter not only the vegetative tissue shape and size, flower size, and greater resistance to both biotic and abiotic stresses, but also the metabolite content in polyploid plants [36]. In this study, our acute toxicity assays on C. quinquefasciatus and S. littoralis larvae demonstrated that the altered tetraploid of T. vulgaris essential oil is more toxic for both types of insects than the essential oil obtained from the diploid (reference) plant. Several works [23,24,37] described significant results for the acute toxicity of EOs and their effects on C. quinquefasciatus and $S$. littoralis larvae. In our study, five terpene compounds (trans-caryophyllene, carvacrol, thymol, UN3, and UN5) comprised higher proportions of the essential oil from the tetraploid clone. Thus, these compounds are likely responsible for its higher toxicity. In conclusion, our findings confirmed the prediction that chromosome doubling in plants can increase content of biologically active compounds isolated from thyme.

\section{Conclusions}

In this work, we proposed a suitable protocol for the in vitro polyploidization of Thymus vulgaris by oryzalin, followed by micropropagation of polyploid plants, their sprouting, and transplanting to ex vitro and field conditions. The experimental success of polyploidization was verified by flow cytometry analysis. The obtained polyploid lines represent new breeding materials that could also increase genetic variability in thyme 
variants; this method of polyploidization could be applied for the genomic manipulation of other medicinal plants. The new tetraploid materials were tested for increases in the contents of biologically active substances (thymol, $\gamma$-terpinene, 4-cymene, etc.), and they were found to be useful for the food industry and as botanical insecticides.

Author Contributions: All co-authors worked on presented research and manuscript in following parts: B.N.-main design of experiments, in vitro cultures, writing manuscript; M.Š.- design of experiments, flow cytometric analyses, writing manuscript; J.B.-GC/MS analyses; V.O.—design of experiments, writing manuscript. All authors have read and agreed to the published version of the manuscript.

Funding: This research was supported by the grants QK1910103 (NAZV, Ministry of Agriculture, Czech Republic) and also by the Ministry of Education, Youth and Sports of the Czech Republic within the National Sustainability Program I (NPU I), grant no. LO1415.

Institutional Review Board Statement: Not applicable.

Informed Consent Statement: Not applicable.

Data Availability Statement: The data presented in this study are available on request from the corresponding author.

Acknowledgments: We thank Roman Pavela for assistance with bioassays concerning toxicity on the C. quinquefasciatus and S. littoralis.

Conflicts of Interest: The authors declare no conflict of interest.

\begin{abstract}
Abbreviations
BA-6-benzyladenine; CMNS-Cultivation of nodal segments on oryzalin medium; DAPI-4' ${ }^{\prime}$ 6diamidino-2-phenylindole; EOs-essential oils; FCM-Flow cytometry; GC/MS—gas chromatography with mass spectra detector; IBA-Indole-3-butyric acid; MS-Murashige and Skoog (1962); ONS-Overflow of nodal segments; PCA—-principal component analysis; PPM-Plant preservative mixture; RSD—relative standard deviation.
\end{abstract}

\title{
References
}

1. Nickavar, B.; Mojab, F.; Dolat-Abadi, R. Analysis of the essential oils of two Thymus species from Iran. Food Chem. 2005, 90, 609-611. [CrossRef]

2. Rota, M.C.; Herrera, A.; Martínez, R.M.; Sotomayor, J.A.; Jordán, M.J. Antimicrobial activity and chemical composition of Thymus vulgaris, Thymus zygis and Thymus hyemalis essential oils. Food Control. 2008, 19, 681-687. [CrossRef]

3. Satyal, P.; Murray, B.L.; McFeeters, R.L.; Setzer, W.N. Essential Oil Characterization of Thymus vulgaris from Various Geographical Locations. Foods 2016, 5, 70. [CrossRef]

4. Liu, Q.; Meng, X.; Li, Y.; Zhao, C.-N.; Tang, G.-Y.; Li, H.-B. Antibacterial and Antifungal Activities of Spices. Int. J. Mol. Sci. 2017, 18, 1283. [CrossRef]

5. Mancini, E.; Senatore, F.; Del Monte, D.; De Martino, L.; Grulova, D.; Scognamiglio, M.; Snoussi, M.; De Feo, V. Studies on Chemical Composition, Antimicrobial and Antioxidant Activities of Five Thymus vulgaris L. Essential Oils. Molecules 2015, 20, 12016-12028. [CrossRef]

6. Aicha, N.; Rachida, T.C.; Abdelmalek, E.L.M. Micropropagation of Thymus satureoides Coss. an endangered medicinal plant of Morocco. J. Agric. Tech. 2013, 9, 487-501.

7. Rout, G.; Samantaray, S.; Das, P. In vitro manipulation and propagation of medicinal plants. Biotechnol. Adv. 2000, 18, 91-120. [CrossRef]

8. Coelho, N.; Gonçalves, S.; González-Benito, M.E.; Romano, A. Establishment of an in vitro propagation protocol for Thymus lotocephalus, a rare aromatic species of the Algarve (Portugal). Plant Growth Regul. 2011, 66, 69-74. [CrossRef]

9. Affonso, V.R.; Bizzo, H.R.; Lage, C.L.S.; Sato, A. Influence of Growth Regulators in Biomass Production and Volatile Profile of in Vitro Plantlets of Thymus vulgaris L. J. Agric. Food Chem. 2009, 57, 6392-6395. [CrossRef] [PubMed]

10. Ozudogru, E.A.; Kaya, E.; Kirdok, E.; Issever-Ozturk, S. In vitro propagation from young and mature explants of thyme (Thymus vulgaris and T. longicaulis) resulting in genetically stable shoots. Vitr. Cell. Dev. Biol. Anim. 2011, 47, 309-320. [CrossRef]

11. Furmanowa, M.; Furmanowa, M.; Olszowska, O.; Olszowska, O. Micropropagation of Thyme (Thymus vulgaris L.). In Biotechnology in Agriculture and Forestry; Bajaj, Y.P.S., Ed.; Springer: Berlin, Germany, 1992; Volume 19, pp. 230-243. 
12. Tosca, A.; Pandolfi, R.; Citterio, S.; Fasoli, A.; Sgorbati, S. Determination by flow cytometry of the chromosome doubling capacity of colchicine and oryzalin in gynogenetic haploids of gerbera. Plant Cell Rep. 1995, 14, 455-458. [CrossRef]

13. Van Duren, M.; Morpurgo, R.; Dolezel, J.; Afza, R. Induction and verification of autotetraploids in diploid banana (Musa acuminata) by in vitro techniques. Euphytica 1996, 88, 25-34. [CrossRef]

14. De Carvalho, J.F.R.P.; Carvalho, C.R.D.P.D.; Otoni, W.C. In vitro induction of polyploidy in annatto (Bixa orellana). Plant Cell Tissue Organ Cult. (PCTOC) 2005, 80, 69-75. [CrossRef]

15. Kermani, M.J.; Sarasan, V.; Roberts, A.V.; Yokoya, K.; Wentworth, J.; Sieber, V.K. Oryzalin-induced chromosome doubling in Rosa and its effect on plant morphology and pollen viability. Theor. Appl. Genet. 2003, 107, 1195-1200. [CrossRef] [PubMed]

16. Wan, Y.; Petolino, J.F.; Widholm, J.M. Efficient production of doubled haploid plants through colchicine treatment of antherderived maize callus. Theor. Appl. Genet. 1989, 77, 889-892. [CrossRef] [PubMed]

17. Hansen, A.; Gertz, A.; Joersbo, M.; Andersen, S. Antimicrotubule herbicides for in vitro chromosome doubling in Beta vulgaris L. ovule culture. Euphytica 1998, 101, 231-237. [CrossRef]

18. Tavan, M.; Mirjalili, M.H.; Karimzadeh, G. In vitro polyploidy induction: Changes in morphological, anatomical and phytochemical characteristics of Thymus persicus (Lamiaceae). Plant Cell Tissue Organ Cult. 2015, 122, 573-583. [CrossRef]

19. Pavela, R.; Sedlák, P. Post-application temperature as a factor influencing the insecticidal activity of essential oil from Thymus vulgaris. Ind. Crop. Prod. 2018, 113, 46-49. [CrossRef]

20. Murashige, T.; Skoog, F. A revised medium for rapid growth and bioassays with tobacco tissue cultures. Physiol. Plant. 1962, 15, 473-497. [CrossRef]

21. Greplová, M.; Polzerová, H.; Domkářová, J. Intra- and inter-specific crosses of Solanum materials after mitotic polyploidization in vitro. Plant Breeding 2009, 128, 651-657. [CrossRef]

22. Doležel, J.; Greilhuber, J.; Suda, J. Estimation of nuclear DNA content in plants using flow cytometry. Nat. Protoc. 2007, 2, 2233-2244. [CrossRef]

23. Pavela, R. Acute toxicity and synergistic and antagonistic effects of the aromatic compounds of some essential oils against Culex quinquefasciatus Say larvae. Parasitol. Res. 2015, 114, 3835-3853. [CrossRef]

24. Pavela, R. Acute, synergistic and antagonistic effects of some aromatic compounds on the Spodoptera littoralis Boisd. (Lep., Noctuidae) larvae. Ind. Crop. Prod. 2014, 60, 247-258. [CrossRef]

25. Abbott, W.S. A method of computing the effectiveness of an insecticide. J. Econ. Entomol. 1925, 18, 265-267. [CrossRef]

26. Majdi, M.; Karimzadeh, G.; Malboobi, M.A.; Omidbaigi, R.; Mirzaghaderi, G. Induction of Tetraploidy to Feverfew (Tanacetum parthenium Schulz-Bip.): Morphological, Physiological, Cytological, and Phytochemical Changes. HortScience 2010, 45, 16-21. [CrossRef]

27. Viehmannová, I.; Trávníčková, M.; Špatenková, E.; Cerna, M.; Trávníček, P. Induced polyploidization and its influence on yield, morphological, and qualitative characteristics of microtubers in Ullucus tuberosus. Plant Cell Tissue Organ Cult. 2011, 109, 83-90. [CrossRef]

28. Dhooghe, E.; Van Laere, K.; Eeckhaut, T.; Leus, L.; Van Huylenbroeck, J. Mitotic chromosome doubling of plant tissues in vitro. Plant Cell Tissue Organ Cult. 2011, 104, 359-373. [CrossRef]

29. Dhooghe, E.; Grunewald, W.; Leus, L.; Van Labeke, M.-C. In vitro polyploidisation of Helleborus species. Euphytica 2009, 165, 89-95. [CrossRef]

30. Gomes, S.S.L.; Saldanha, C.W.; Neves, C.S.; Trevizani, M.; Raposo, N.R.B.; Notini, M.M.; Santos, M.D.O.; Campos, J.M.S.; Otoni, W.C.; Viccini, L.F. Karyotype, genome size, and in vitro chromosome doubling of Pfaffia glomerata (Spreng.) Pedersen. Plant Cell Tissue Organ Cult. 2014, 118, 45-56. [CrossRef]

31. Shmeit, Y.H.; Fernandez, E.; Novy, P.; Kloucek, P.; Orosz, M.; Kokoska, L. Autopolyploidy effect on morphological variation and essential oil content in Thymus vulgaris L. Sci. Hortic. 2020, 263, 109095. [CrossRef]

32. Stanys, V.; Weckman, A.; Staniene, G.; Duchovskis, P. In vitro induction of polyploidy in japanesse quince (Chaenomeles japonica). Plant Cell Tiss. Organ Cult. 2006, 84, 263-268. [CrossRef]

33. Quesenberry, K.H.; Dampier, J.M.; Lee, Y.Y.; Smith, R.L.; Acuna, C.A. Doubling the chromosome number of bahiagrass via tissue culture. Euphytica 2010, 175, 43-50. [CrossRef]

34. Švécarová, M.; Navrátilová, B.; Ondřej, V. In vitro polyploidization of Ajuga reptans L. using oryzalin. Acta Biol. Crac. Ser. Bot. 2018, 60, 69-73.

35. Švécarová, M.; Navrátilová, B.; Hašler, P.; Ondřej, V. Artificial induction of tetraploidy in Humulus lupulus L. using oryzalin. Acta Agrobot. 2019, 72, 1764. [CrossRef]

36. Salma, U.; Kundu, S.; Mandal, N. Artificial polyploidy in medicinal plants: Advancement in the last two decades and impending prospects. J. Crop. Sci. Biotechnol. 2017, 20, 9-19. [CrossRef]

37. Benelli, G.; Pavela, R.; Canale, A.; Cianfaglione, K.; Ciaschetti, G.; Conti, F.; Nicoletti, M.; Senthil-Nathan, S.; Mehlhorn, H.; Maggi, F. Acute larvicidal toxicity of five essential oils (Pinus nigra, Hyssopus officinalis, Satureja montana, Aloysia citrodora and Pelargonium graveolens) against the filariasis vector Culex quinquefasciatus: Synergistic and antagonistic effects. Parasitol. Int. 2017, 66, 166-171. [CrossRef] 